\title{
Antimicrobial resistance and virulence gene profiles in $P$. multocida strains isolated from cats
}

\author{
Thais Sebastiana Porfida Ferreira, Maria Roberta Felizardo, \\ Debora Dirani Sena de Gobbi, Marina Moreno, Andrea Micke Moreno
}

Laboratório de Epidemiologia Molecular e Resistencia a Antimicrobianos, Faculdade de Medicina Veterinária e Zootecnia, Universidade de São Paulo, São Paulo, SP, Brazil.

Submitted: January 29, 2014; Approved: June 6, 2014.

\begin{abstract}
Cats are often described as carriers of Pasteurella multocida in their oral microbiota. This agent is thought to cause pneumonia, conjunctivitis, rhinitis, gingivostomatitis, abscess and osteonecrosis in cats. Human infection with $P$. multocida has been described in several cases affecting cat owners or after cat bites. In Brazil, the cat population is approximately 21 million animals and is increasing, but there are no studies of the presence of $P$. multocida in the feline population or of human cases of infection associated with cats. In this study, one hundred and ninety-one healthy cats from owners and shelters in São Paulo State, Brazil, were evaluated for the presence of $P$. multocida in their oral cavities. Twenty animals were positive for $P$. multocida, and forty-one strains were selected and characterized by means of biochemical tests and PCR. The P. multocida strains were tested for capsular type, virulence genes and resistance profile. A total of $75.6 \%$ (31/41) of isolates belonged to capsular type A, and $24.4 \%(10 / 41)$ of the isolates were untypeable. None of the strains harboured toxA, tbp $A$ or $p f h A$ genes. The frequencies of the other genes tested were variable, and the data generated were used to build a dendrogram showing the relatedness of strains, which were clustered according to origin. The most common resistance profile observed was against sulfizoxazole and trimethoprimsulphamethoxazole.
\end{abstract}

Key words: cat, Pasteurela multocida, virulence genes, resistance, isolation.

\section{Introduction}

Pasteurella multocida is an important pathogen that infects a wide range of animal hosts and is a member of the microbiota of the superior respiratory tract of different animal species (Dziva et al., 2008). Cats are frequently described as healthy carriers of $P$. multocida. Because of their hunting habits and because they are usually involved in fights causing scratches or bites, the carriers spread the bacterium among the cat population.

Cat bites often infect humans with P. multocida, resulting in cellulitis and lymphangitis, sometimes complicated by abscess formation, peritonitis and septic arthritis. Case reports of infection by $P$. multocida in patients with a compromised immune response in contact with cats with- out bite history are becoming common (Hey et al., 2012; Sol et al., 2013).

P. multocida is also described as a causative agent of pneumonia, conjunctivitis, rhinitis, gingivostomatitis, abscess and osteonecrosis in cats (Ewers et al., 2006). Dolieslager et al. (2010) report that $P$. multocida is significantly more prevalent in cats presenting gingivostomatitis than in normal cats and can be of etiological significance in this disease.

Capsular serotypes A, D and F are the most frequently isolated serotypes from cats and different virulence factors were described by Ewers et al. (2006) in cat strains. The pathogenicity of $P$. multocida has been associated with different virulence factors, such as capsules, adhesins, toxins, siderophores, sialidases and outer membrane proteins.

Send correspondence to A.M. Moreno. Laboratório de Epidemiologia Molecular e Resistência a Antimicrobianos, Faculdade de Medicina Veterinária e Zootecnia, Universidade de São Paulo, Av. Prof. Dr. Orlando Marques de Paiva 87, Cidade Universitária, 05508270 São Paulo, SP, Brazil. E-mail: morenoam@usp.br. 
These virulence factors improve the colonization and invasion of the host, the avoidance or disruption of host defense mechanisms, injury to host tissues, and/or stimulation of a noxious host inflammatory response (Tang et al., 2009).

This is the first report of P. multocida isolation from carrier cats in Brazil. The aim of this study was evaluate the occurrence of $P$. multocida in healthy cats, determine the resistance profile and investigate the presence of the virulence genes encoding for outer membrane and porin proteins (oma87, ompH, plpB, psl), adhesins ( $p t f A$, fimA, hsf-1, $h s f-2, p f h A, \operatorname{tad} D)$, neuraminidases (nan $B, n a n H)$, iron acquisition related factors (exBD, tonB, fur, pmHAS, tbp $A$, $h g b A, h g b B)$, superoxide dismutases ( $\operatorname{sod} A$, $\operatorname{sod} C)$, dermonecrotoxin (toxA), and hyaluronidase (pmHAS).

\section{Material and Methods}

\section{Sample collection and processing}

The samples were collected in February 2008 and February 2011 with sterile swabs from the gingiva of one hundred and ninety-one cats from owners and shelters in São Paulo State. The swabs were placed in Amies transport medium and kept under refrigeration for $24 \mathrm{~h}$ until analysis (Copan Diagnostics Inc., CA, USA).

Each swab was plated on tryptic soy yeast extract agar (Difco-BBL) supplemented by $5 \%$ of defibrinated sheep blood and incubated at $37{ }^{\circ} \mathrm{C}$ for $24 \mathrm{~h}$. From each plate, one to five colonies with morphology suggestive of $P$. multocida were selected. Colonies were identified using standard biochemical procedures, including the production of catalase, oxidase, and indol, urease activity, the production of ornithine decarboxylase, carbohydrate fermentation (Mutters et al., 1989) and PCR for the detection of the species-specific gene fragment $k m t$ (Townsend et al., 1998).

\section{Antimicrobial susceptibility testing}

The susceptibility profile was established by a disc diffusion test as recommended by the Clinical and Laboratory Standards Institute (VET01-A4, 2013). The antimicrobial agents tested included ceftiofur, penicillin, amoxicillin, flofenicol, norfloxacin, enrofloxacin, ciprofloxacin, tetracycline, doxycycline, sulfizoxazole, trimethoprimsulphamethoxazole and erythromycin (Oxoid Ltd., Cambridge, UK). The reference strains Escherichia coli ATCC 25922 and Staphylococcus aureus ATCC 29213 were used as quality control organisms in all antimicrobial susceptibility tests. There are no CLSI approved breakpoints applicable specifically to feline Pasteurella multocida; therefore, most of the values used here originated from values described in CLSI document VET01-A4 and supplement VET01-S2. The breakpoints used for doxycycline, ciprofloxacin and norfloxacin were adopted from CLSI document M100- S19 (2009).

\section{DNA preparation}

Bacteria were cultured overnight in brain hearth infusion (BHI) broth at $37^{\circ} \mathrm{C}$ and $200 \mu \mathrm{L}$ of this bacterial suspension was submitted to the DNA extraction procedure described by Boom et al. (1990).

\section{PCR analyses and gel electrophoresis}

P. multocida strains were evaluated by PCR for the identification (using the $k m t$ gene) and presence of the capsule biosynthesis genes cap $A, B, D, E$ and $F$ as described by Townsend et al. (1998). The virulence-related genes oma87, отрH, plpB, psl, ptfA, fimA, hsf-1, hsf-2, pfhA, tadD, nan B, nan $\mathrm{H}$, exBD/tonB, fur, pmHAS, tbpA, hgbA, $h g b B, \operatorname{sod} A, \operatorname{sod} C, \operatorname{tox} \mathrm{A}$, and $p m H A S$ were described by Ewers et al. (2006) and Tang et al. (2009). The combination of different genes in multiplex reactions was standardized in this study (Table 1). The following P. multocida strains were used as positive controls: ATCC 12945, ATCC 12948 and NCTC 10323.

For all reactions, $5 \mu \mathrm{L}$ of DNA template was added to the $45 \mu \mathrm{L}$ mixture containing 20 pmoles of each primer pair, $1.5 \mathrm{mM}$ of $\mathrm{MgCl}_{2}, 200 \mathrm{mM}$ of each dNTP, $1 \mathrm{U}$ of Taq DNA polymerase (Fermentas Inc., Maryland, USA), 1X PCR buffer and ultra-pure water. The PCR conditions were carried out according to the respective authors' protocols. The amplified products were subjected to electrophoresis in a $1.5 \%$ agarose gel, stained with BlueGreen ${ }^{\circledR}$ (LGC Biotecnologia, Cotia, SP, Brazil), and identified using a 100 bp DNA ladder.

\section{Statistical analysis}

Relatedness among P. multocida strains was determined by a comprehensive pair-wise comparison of different gene combinations using the Dice coefficient by means of the Bionumerics 6.6 software (Applied Maths NV, SintMartens-Latem, Belgium) to generate the dendrogram.

Table 1 - Distribution of genes evaluated in single gene PCR or multiplex PCR and the size of the expected products.

\begin{tabular}{lcc}
\hline PCR & Gene & Amplicon (bp) \\
\hline E1 & kmt 1 & 560 \\
C1 & hyaD-hyaC, bcbD, dcbF, ecbJ, fcbD & $1.044,760,657,511,851$ \\
FV1 & hgbA, ptfA, hgbB, exbBD/ tonB & $419,488,788,1144$ \\
FV2 & nanH, psl, nanB & $360,439,584$ \\
FV3 & ompH, oma87 & 438,949 \\
F4 & pfhA, sodC & 275,235 \\
FV5 & sodA & 361 \\
FV 6 & tbPA & 728 \\
FV 7 & fimA, pmHAS, OmpA & $866,430,201$ \\
FV 8 & hsf1, hsf2, fur & $654,433,244$ \\
FV 9 & tadD, plpB & 416,282 \\
\hline
\end{tabular}




\section{Results}

Of the animals, $10.5 \%$ were positive for $P$. multocida isolation (20/191) and forty-one strains were selected for PCR characterization and antimicrobial susceptibility testing. Thirty-one strains were characterized as type capsular $\mathrm{A}$ and ten were untypeable using PCR as described by Towsend et al. (1998). The frequency of different virulence genes is presented in Table 2 and the profiles generated through gene combinations are shown in Figure 1. In the dendrogram, the numbers that identify the strains are representative of the examined animals. The strains from the same animals in several cases presented different virulence gene profiles. Strains 94.1, 94.3 and 94.4, for example, were isolated from the same cat, but present a different combination of virulence genes and different resistance patterns.

The frequency of antimicrobial resistance is described in table 3. Of the forty-one selected strains, $12.1 \%$ $(5 / 41)$ were susceptible to all tested drugs, and $87.8 \%$ $(36 / 41)$ were resistant to at least one drug tested. The resistance was more frequent to trimethoprim-sulphamethoxazole $(75.6 \%)$, followed by sulfizoxazole $(60.9 \%)$.

\section{Discussion}

Although P. multocida is frequently reported in feline oral microbiota and isolated in cat bites (Goldstein et al., 2012), the literature contains no data about the occurrence, presence of virulence genes or resistance profiles in $P$. multocida strains from cats in Brazil.

The frequency of $P$. multocida observed in this study $(10.4 \%)$ was much lower than that reported by Freshwater (2008), who found $89.9 \%$ of positive samples in the gingival mucosa of cats $(368 / 409)$. This difference could be related to the culture media used, interference of competitive oral microbiota or geographical differences.

In this study, tryptic soy yeast extract agar containing $5 \%$ of defibrinated sheep blood without antibiotics was used, while Freshwater (2008) used the same media with 5 $\mathrm{mg} / \mathrm{L}$ of clindamycin. The choice of do not include antibiotic at the culture media in this study, was done because in a pilot study a poor growth of bacteria on blood agar plates was observed, instead an overgrowth of bacteria from microbiota that could make the isolation of $P$. multocida colonies more difficult (data not shown).

$P$. multocida infections are often treated with broadspectrum antimicrobials (Kehrenberg et al., 2001). Resistance profile showed that cephalosporin, fluorquinolones and florfenicol are the most efficient drugs to be used

Table 2 - Frequency of protein-coding genes and virulence factors in P. multocida strains isolated from cats.

\begin{tabular}{|c|c|c|}
\hline Gene & Virulence factor & No of positives $(\%)$ \\
\hline $\operatorname{tox} A$ & Dermonecrotic Toxin & $0 / 41(0.0)$ \\
\hline$p f h A$ & Filamentous hemagglutinin & $0 / 41(0.0)$ \\
\hline$h g b A$ & Hemoglobin-binding protein & $25 / 41(60.9)$ \\
\hline$h g b B$ & Hemoglobin-binding protein & $35 / 41(85.3)$ \\
\hline $\operatorname{exbBD-\operatorname {ton}B}$ & Iron acquisition & $39 / 41(95.1)$ \\
\hline nanH & Neuraminidase & $34 / 41(82.9)$ \\
\hline Psl & Porin & $38 / 41(92.6)$ \\
\hline $\operatorname{nan} B$ & Neuraminidase & $40 / 41(97.5)$ \\
\hline oomph & Outer membrane protein $\mathrm{H}$ & $39 / 41(95.1)$ \\
\hline oma87 & Outer membrane protein 87 & $41 / 41(100.0)$ \\
\hline$p t f A$ & Type 4 fimbriae & $26 / 41(63.4)$ \\
\hline soda & Superoxide dismutase & $35 / 41(85.3)$ \\
\hline $\operatorname{sod} C$ & Superoxide dismutase & $21 / 41(51.2)$ \\
\hline $\operatorname{tbp} A$ & Transferrin binding protein & $0 / 41(0.0)$ \\
\hline $\operatorname{fim} A$ & Fimbriae & $25 / 41(60.5)$ \\
\hline hsfl & Autotransporter Adhesin & $5 / 41 /(12.1)$ \\
\hline$h s f 2$ & Autotransporter Adhesin & $11 / 41(26.8)$ \\
\hline $\operatorname{tad} D$ & Putative nonspecific tight adherence protein D & 9/41 (21.9) \\
\hline Fur & Ferric uptake regulation protein & $7 / 41(17.0)$ \\
\hline pmHAS & Hyaluronan synthase & $26 / 41(63.4)$ \\
\hline OmpA & Outer membrane protein $\mathrm{A}$ & $14 / 41(34.1)$ \\
\hline plpB & Lipoprotein B & $20 / 41(48.7)$ \\
\hline
\end{tabular}




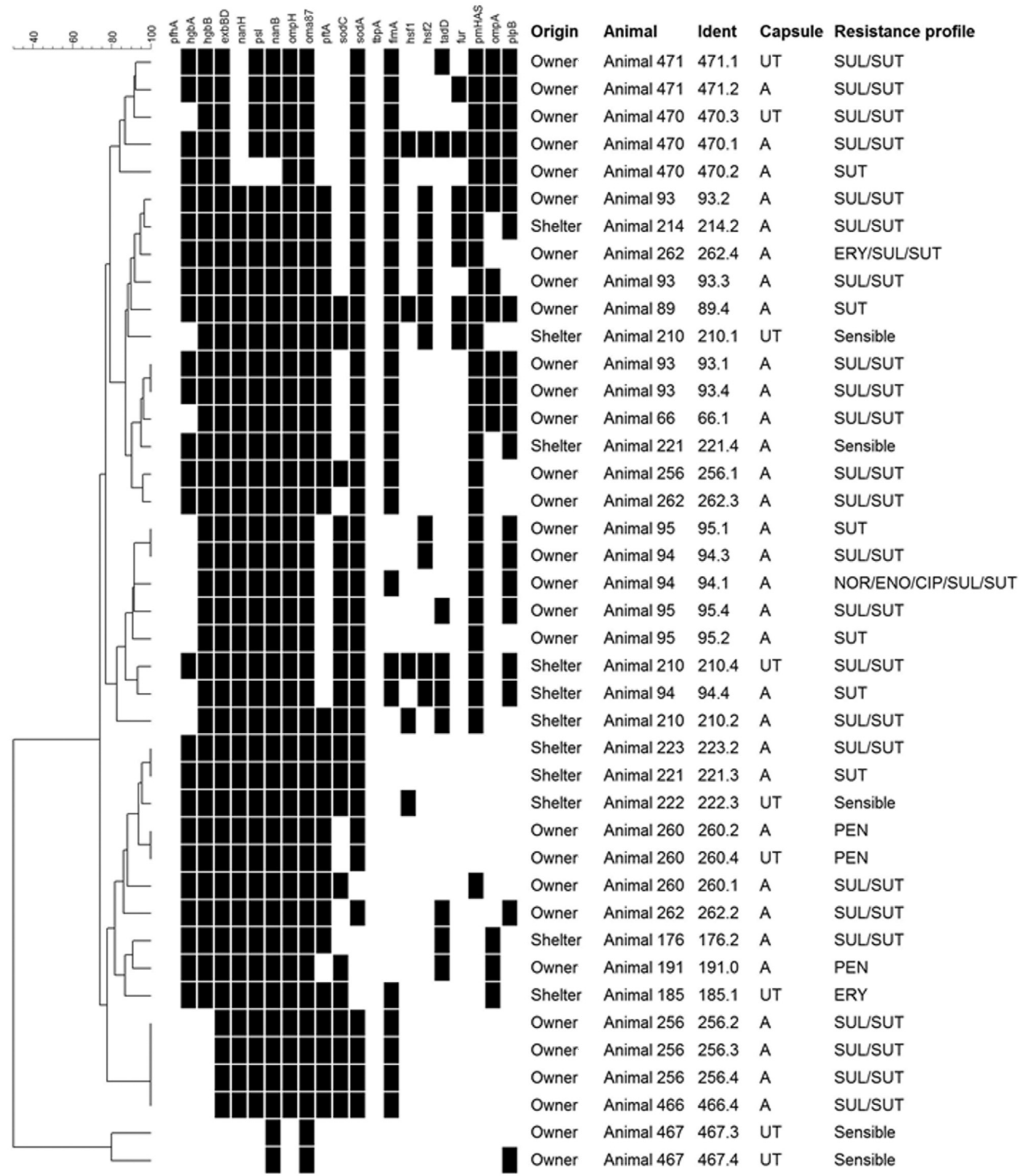

Figure 1 - Dendrogram representing the relatedness of $P$. multocida strains isolated from cats according to their virulence profile.

against $P$. multocida. Similar results have been previously described in Brazil, France, North America and Japan (Rigobelo et al., 2013; Kehrenberg et al., 2001; Salmon et al., 1995; Yoshimura et al., 2001). Resistance to sulfizoxazole and trimethoprim-sulphamethoxazole has been described previously (Tang et al., 2009).
One strain showed an unusual resistance pattern, being resistant to norfloxacin, enrofloxacin, ciprofloxacin, sulfizoxazole and trimethoprim-sulphamethoxazole. Two strains were resistant to erythromycin. Resistance to fluorquinolones is rare in $P$. multocida strains and is most likely due to mutations in the genes gyrA and parC, encoding 
Table 3 - Frequency of antimicrobial resistance in P. multocida strains isolated from cats, disk content and breakpoints used in this study.

\begin{tabular}{|c|c|c|c|c|c|}
\hline \multirow[t]{2}{*}{ Antimicrobial } & \multirow{2}{*}{$\begin{array}{c}\text { Disk content } \\
\qquad(\mu \mathrm{g})\end{array}$} & \multicolumn{3}{|c|}{ Zone Diameter Breakpoints*(mm) } & \multirow[t]{2}{*}{$\mathrm{N}^{\circ}$ of resistant strains (\%) } \\
\hline & & $\mathrm{S}$ & I & $\mathrm{R}$ & \\
\hline Ampicillin & 10 & $\geq 17$ & $14-16$ & $\leq 28$ & $0 / 41(0.0)$ \\
\hline Ceftiofur & 30 & $\geq 21$ & $18-20$ & $\leq 17$ & $0 / 41(0.0)$ \\
\hline Cotrimoxazole & $1.25 / 23.75$ & $\geq 16$ & $11-15$ & $\leq 10$ & $31 / 41(75.6)$ \\
\hline Doxycycline** & 30 & $\geq 16$ & $13-15$ & $\leq 12$ & $0 / 41(0.0)$ \\
\hline Enrofloxacin & 5 & $\geq 23$ & $17-22$ & $\leq 16$ & $1 / 41(2.4)$ \\
\hline Norfloxacin** & 10 & $\geq 17$ & $13-16$ & $\leq 12$ & $1 / 41(2.4)$ \\
\hline Ciprofloxacin** & 5 & $\geq 21$ & $16-20$ & $\leq 15$ & $1 / 41(2.4)$ \\
\hline Erythromycin & 15 & $\geq 23$ & $14-22$ & $\leq 13$ & 2/41 (4.9) \\
\hline Florfenicol & 30 & $\geq 22$ & $19-21$ & $\leq 18$ & $0 / 41(0.0)$ \\
\hline Penicillin & 10 & $\geq 29$ & - & $\leq 28$ & $3 / 41(7.3)$ \\
\hline Sulfizoxazole & 300 & $\geq 17$ & $13-16$ & $\leq 12$ & 25/41 (60.9) \\
\hline Tetracycline & 30 & $\geq 19$ & $15-18$ & $\leq 14$ & $0 / 41(0.0)$ \\
\hline
\end{tabular}

* Trimethoprim/sulphamethoxazole.

** Breakpoints from CLSI - M100- S19 (2009).

DNA gyrase and topoisomerase IV (Michael et al., 2012). Hendriksen et al. (2008) evaluated antimicrobial resistance among bacterial pathogens isolated from cattle in different European countries and described a resistance rate to fluorquinolones of $4.2 \%$ in France in 2002 and a rate of $6.3 \%$ in the Netherlands in 2004. Portis et al. (2012) reported that $P$. multocida isolated from cattle in the United States and Canada had rates of resistance to danofloxacin varying from 8.5 to 13.1 in 2004 and 2009. In the same study, enrofloxacin resistance rates were 2.1 and 3.5 in 2008 and 2009, respectively. The use of fluorquinolones in veterinary clinics, hospitals and shelters is high in Brazil, but it could not be directly related to this resistance profile because it was observed in only one animal, and it was not possible to evaluate its health history.

Erythromycin is a member of the macrolide class of antibiotics. Mechanisms of resistance to this class of antibiotics in P. multocida have been well studied. There are no descriptions of resistance to this antibiotic in companion animals (Schwarz et al., 2007), but Tang et al. (2009) describe $6 \%$ of $P$. multocida strains resistant to erythromycin among 233 strains from swine in China.

Using PCR, 75.6\% (31/41) of the strains were positive for capsular type A, in agreement with reports in the literature as the most common capsular type in cats (Arumugam et al., 2011). A similar frequency of untypeable strains $(24.4 \%)$ was also found using the reaction described by Towsend et al. (1998) compared to the description of Arumugam et al. (2011). These authors reported that $19.3 \%(22 / 114)$ of $P$. multocida strains were untypeable using PCR, while other studies describe frequencies varying from 2 to 9\% (Davies et al., 2003a; 2003b; Ewers et al., 2006; Jamaludin et al., 2005; Tang et al., 2009).

Using traditional serotyping, Arumugam et al. (2011) described a significantly higher percentage of untypeable strains than observed by PCR, reaching 48.2\% (55/114). The expression of capsular type is a critical point for the virulence potential of $P$. multocida strains and can be influenced by different factors, such as antimicrobial presence, iron loss and multiple in vitro passages (Steen et al., 2010). However, explanations for the absence of capsule-related loci (A, B, D, E or F) were not found in the literature.

The frequency of virulence genes varies from zero, for example for iron acquisition-related protein $(\operatorname{tbp} A)$, filamentous hemagglutinin (pfhA) and dermonecrotoxin, to $100 \%$, for example for outer membrane protein (oma 87 ). Sina et al. (2006) report that the tbpA gene is related to bovine infections and that dermonecrotoxin is involved in atrophic rhinitis in swine, justifying the absence of these genes in cat strains. In contrast to this study, Ewers et al. (2006) report that $18.5 \%$ of $P$. multocida strains isolated from cats are positive for filamentous hemagglutinin $(p f h \mathrm{~A})$, but a correlation of this factor with clinical pasteurellosis was established only in bovine strains.

The high frequency of genes encoding for outer membrane proteins (oma $87-100 \%$, ompH - $95.1 \%$ ) is very relevant to the invasion potential of the tested strains because OMPs act as selective barriers preventing the entry of toxic molecules in the cell, which is crucial to bacterial survival in different environments. At the same time, these proteins play different roles in bacteria, such as nutrient absorption, importation and exportation of molecules and a close interaction with host tissue (Hatfaludi et al., 2010). 
Other genes detected at a high frequency were iron acquisition-related factors $(e x B D / \operatorname{ton} B-95.1 \%, h g b A$ $60.9 \%$, $h g b B-85.3 \%$ ), adhesins ( $p t f A-63.4$, fim $A-60.5 \%$, hsf-1 - 12.1\%, hsf-2 - 26.8\%, pfhA - 0\%, tadD - 21.9\%), porin proteins ( $p l p B-48.7 \%, p s l-92.6 \%)$, neuraminidases (nanB - 97.5\%, nanH - 82.9\%), and superoxide dismutase (sodA - 85.3\%, sodC - 51.2\%, fur - 17\%, pmHAS -34.1\%, tbpA - 0\%).

In addition to the zoonotic aspects, it is important to remember that in cats, $P$. multocida is one of the most frequent pathogens present in infected skin wounds and subcutaneous abscesses. It is a common pyothorax-producer in cats and has been associated with spinal empyema and meningoencephalomyelitis (Lloret et al., 2013).

The results described in this study suggest that cats can carry P. multocida in the oral cavity and that isolated strains have considerable virulence gene baggage associated with antimicrobial resistance against drugs used in human and veterinary medicine. Considering the high proximity of cats and owners, the habits of kissing the animals or allowing them free access to the bedroom or kitchen environment, it is important to emphasize the need for hygienic measures to prevent contamination by this agent. In addition to bites and licks, close contact with cats has been enough to cause infection in humans (Lloret et al., 2013).

\section{Acknowledgments}

This study was supported by FAPESP- Fundação de Amparo a Pesquisa do Estado de São Paulo grants 2007/08592-3 and 2007/03024-7, and CAPES Coordenação de Aperfeiçoamento de Pessoal de Nível Superior.

\section{References}

Arumugam ND, Ajam N, Blackall PJ et al. (2011) Capsular serotyping of Pasteurella multocida from various animal host - a comparison of phenotypic and genotypic methods. Trop Biomed 28:55-63.

Boom R, Sol CJA, Salimans MMM et al. (1990) Rapid and simple method for purification of nucleic acids. J Clin Microbiol 28:495-503.

Clinical and Laboratory Standards Institute (2013) Performance Standards for Antimicrobial Disk and Dilution Susceptibility Tests for bacteria Isolated from Animals; Second Informational Supplement. CLSI Document VET01-S2, Wayne.

Clinical and Laboratory Standards Institute (2013) Performance Standards for Antimicrobial Disk and Dilution Susceptibility Tests for bacteria Isolated from Animals; Approved Standard- Fourt Edition. CLSI document VET01-A4, Wayne.

Davies RL, Maccorquodale R, Baillie S et al. (2003) Characterization and comparison of Pasteurella multocida strains associated with porcine pneumonia and atrophic rhinitis. J Med Microbiol 52:59-67.
Davies RL, Maccorquodale R, Baillie S et al. (2003b) Diversity or avian Pasteurella multocida strains based on capsular PCR typing and variation of the OmpA and $\mathrm{OmpH}$ outher membrane proteins. Vet Microbiol 91:169-182.

Dolieslager SM, Riggio MP, Lennon A et al. (2011) Identification of bacteria associated with feline chronic gingivostomatitis using culture dependent and culture independent methods. Vet Microbiol 148:93-98.

Dziva F, Muhairwa AP, Bisgaard M et al. (2008) Diagnostic and typing options for investigating diseases associated with Pasteurella multocida. Vet Microbiol 128:1-22.

Ewers C, Lubke-Becker A, Bethe A et al. (2006) Virulence genotype of Pasteurella multocida strains isolated from different hosts with various disease status. Vet Microbiol 114:304317.

Freshwater A (2008) Why your housecat's trite little bite could cause you quite a fright: a study of domestic felines on the occurrence and antibiotic susceptibility of Pasteurella multocida. Zoonoses Public Health 55:507-513.

Goldstein EJC, Citron DM, Merriam CV et al. (2012) Ceftaroline vs. isolates from animal bite wounds: comparative in vitro activities against 243 isolates, including 156 Pasteurella species isolates. Antimicrob Agents Chemother 56:6319-6323.

Hatfaludi T, Al-Hasani K, Boyce JD et al. (2010) Outer membrane proteins of Pasteurella multocida. . Vet Microbiol 144:1-17.

Hey P, Gow P, Torresi J et al. (2012) Cirrhosis, cellulitis and cats: a 'purrfect' combination for life-threatening spontaneous bacterial peritonitis from Pasteurella multocida. BMJ Case Report doi: 10.1136/bcr-2012-007397.

Hendriksen RS, Mevius DJ, Schroeter A et al. (2008) Prevalence of antimicrobial resistance among bacterial pathogens isolated from cattle in different European countries: 20022004. Acta Vet Scand 50:28.

Jamaludin R, Blackall PJ, Hansen MF et al. (2005) Phenotypic and genotypic characterization of Pasteurella multocida isolated from pigs at slaughter in New Zeland. N Z Vet J 53:203-207.

Kehrenberg CG, Schulze-Tanzil JL, Martel E et al. (2001) Antimicrobial resistance in Pasteurella and Mannheimia: epidemiology and genetic basis. Veterinary Resources 32:323-339.

Lloret A, Egberink H, Addie D et al. (2013) Pasteurella multocida infection in cats: ABCD guidelines on prevention and management. J Feline Med Surg 15:570-572.

Michael GB, Kadlec K, Sweeney MT et al. (2012) ICEPmu1, an integrative conjugative element (ICE) of Pasteurella multocida: analysis of the regions that comprise 12 antimicrobial resistance genes. J Antimicrob chemother 67:8490.

Mutters R, Mannheim W, Bisgaard M (1989) Taxonomy of the group. In: C. Adlan, J.M. Rutter (eds) Pasteurella and Pasteurellosis. Academic Press Limited, London, pp 3-34.

Portis E, Lindeman C, Johansen L et al. (2012) A ten-year (2000-2009) study of antimicrobial susceptibility of bacteria that cause bovine respiratory disease complex-Mannheimia haemolytica, Pasteurella multocida, and Histophilus somni-in the United States and Canada. J Vet Diagn Invest 24:932-944. 
Rigobelo EC, Blackall PJ, Maluta RP et al. (2013) Identification and antimicrobial susceptibility patterns of Pasteurella multocida isolated from chickens and japanese quails in Brazil. Braz J Microbiol 44:161-164.

Salomon SAJL, Watts CA, Case 1J et al. (1995) Comparison of MICs of ceftiofur and other antimicrobial agents against bacterial pathogens of swine from United States, Canada and Denmark. J Clin Microbiol 33:2435-2444.

Schwarz S, Alesik E (2007) Antimicrobial susceptibility of Pasteurella multocida and Bordetella bronchiseptica from dogs and cats as determined in the BfT-GermVet monitoring program. Berliner und Münchener Tierärztliche Wochesnschrift 120:423-430.

Sina A, Jalal S, Mohammad SH (2009) Rapid virulence typing of Pasteurella multocida by multiplex PCR. Res Vet Sci 87:355-357.

Sol PM, Van De Kar NC, Schreuder MF (2013) Cat induced Pasteurella multocida peritonitis in peritoneal dialysis: a case report and review of the literature. Int J Hyg Environ Health 216:211-213.

Steen JA, Harrison P, Seemann T et al. (2010) Fis Is Essential for capsule production in Pasteurella multocida and regulates expression of other important virulence factors. PLoS Pathogens 6:1-14.

Tang X, Zhao Z, Hu J et al. (2009) Isolation, Antimicrobial Resistance, and Virulence Genes of Pasteurella multocida Strains from Swine in China. J Clin Microbiol 47:951-958.

Towsend KM, Frost AJ, Lee CW et al. (1998) Development of PCR assays for species- and type-specific identification of Pasteurella multocida isolates. J Clin Microbiol 36:1096-1100.

Yoshimura HM, Ishimura YSE, Kojima A (2001) Antimicrobial susceptibility of Pasteurella multocida isolated from cattle and pigs. J Vet Med B 48:555-560.

Associate Editor: Walter Lilenbaum

All the content of the journal, except where otherwise noted, is licensed under a Creative Commons License CC BY-NC. 